\title{
THE VIRTUAL 3D RECONSTRUCTION OF THE EAST PEDIMENT OF THE TEMPLE OF ZEUS AT OLYMPIA - PRESENTATION OF AN INTERACTIVE CD-ROM
}

\author{
András PATAY-HORVÁTH \\ University Eötvös Loránd, Institute for Ancient History - Archaeological Institute of the Hungarian \\ Academy of Sciences, Budapest, Hungary \\ pathorv@gmail.com
}

Keywords: Archaeology, ancient Greek marble sculpture, 3D scanning, virtual modeling

\begin{abstract}
The paper gives an overview of a two-years project concerning a major monument of ancient Greek art and presents the interactive, bilingual (English/Hungarian) CD-ROM, which is intended to summarize and visualize its final results. The presented project approaches a century-old controversy in a new way by producing a virtual 3D reconstruction of a monumental marble group. Digital models of the statues were produced by scanning the original fragments and by reconstructing them virtually. The virtual model of the pediment surrounding the sculptures was prepared on the basis of the latest architectural studies and afterwards the reconstructed models were inserted in this frame, in order to test the technical feasibility and aesthetic effects the four possible arrangements. The resulting models enable easy and very instructive experimentation, which would be otherwise impossible with the originals and/or very expensive and not very practicable with traditional tools (e.g. real-size plaster models). The complete model can effectively be used to verify the results of earlier or more recent reconstructions presented only in simple drawings. In addition, the 3D models of the individual fragments can be used for further research and for visualization. The documentary CD-ROM presenting the full background, the methods and the conclusions of the project contains beside a comprehensive text various kinds of supporting documents (images, 3D models, papers, broadcasts, audiovisual material). It is addressed to a mixed audience: a picture gallery, a short documentary movie some other attachments including a selected bibliography is intended for the general public, but scholarly publications, presentations on related problems are also included for specialists interested in certain details.
\end{abstract}

\section{INTRODUCTION}

\subsection{The subject}

The temple of Zeus at Olympia was built in the first half of the 5th century B.C. (ca. 475-455). Its sculptural decoration consists of two pediments and twelve metopes. Given the large size of the building itself, the sculptures were all well over life-size and were made of white parian marble. Most of them are quite well preserved and are depicted in practically every handbook on Greek art or on ancient art in general. The sculptures of the temple in general and the fragments of the east pediment (Figure 1) in particular have been thoroughly studied since their discovery in the 1880's, but they still pose some important questions, as indicated by the growing number of monographs and scholarly articles related to them $[1,2,3,4,5,6,7]$. The most recent debate has started with a series of publications by the author $[8,9$, $10,11]$ and concerns the interpretation of the east pediment, which involves the problematic issue of the correct reconstruction of this group as well.

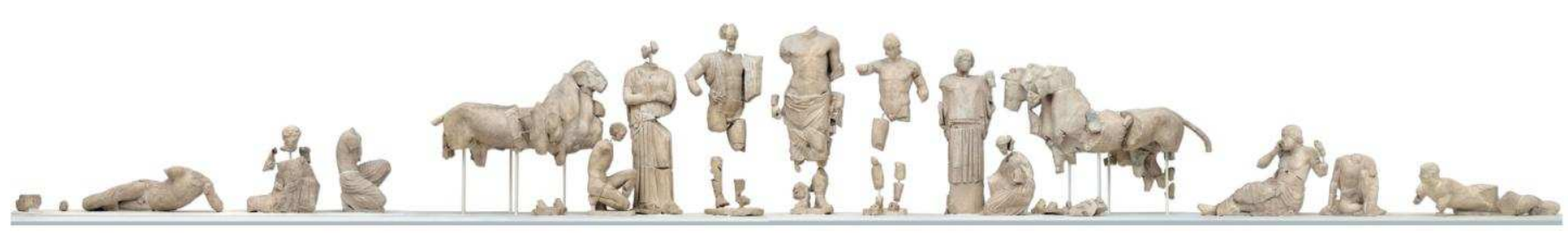

Figure 1: Fragments of the east pediment, as displayed in the Archaeological Museum of Olympia today 


\subsection{The problem}

The arrangement of the five central figures of the east pediment has been the subject of scholarly debates since the discovery of the fragments more than a century ago $[5,11]$. The basic problem is that the fragments themselves can be arranged in four substantially different ways and there are no obvious clues for choosing the most probable one. There is a fairly detailed description of the group by Pausanias, who saw it in the 2nd cent. AD, but his text (Description of Greece, book V, ch. 10, 6-7) is not conclusive regarding the precise arrangement of the figures (he does not specify how to understand his indications ,to the left” and „to the right” of the central figure). The find places are not unequivocal either, since the pieces were scattered around the temple by an earthquake in the 6th cent. AD and the fragments were subsequently reused in medieval buildings. In sum, there are four different arrangements, all of which have already been advocated by certain scholars for various aesthetic, technical and other considerations. Most often the reconstructions are presented in simple drawings, ignoring the three-dimensional form of the statues (Figure 2).
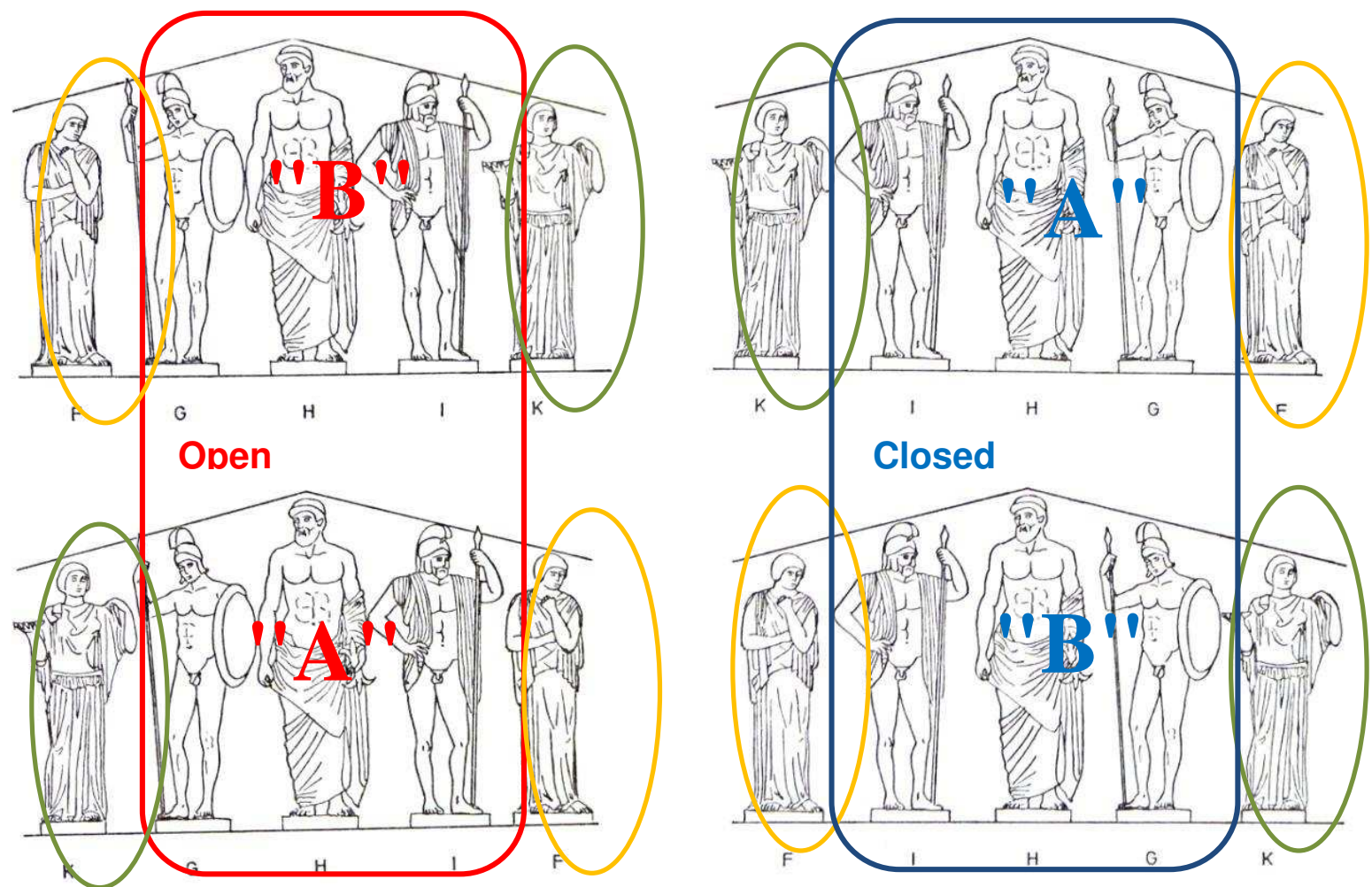

Figure 2. The central part of the pediment enlarged. Schematic reconstruction drawings showing every conceivable arrangement of the five central figures. Different colours highlight the differences of the four versions. After Herrmann 1972.

\subsection{Brief history of research}

Since the original fragments are insufficient to answer the question and their enormous size and weight make experimentation practically impossible, scholars had to approach the problem in a different way. At the end of the 19th century, plaster models of the statues were produced first on a reduced scale (1:10), then on the actual scale (1:1) and lost body parts, arms, etc. were reconstructed as well. Experimenting with the plaster models for several years, G. Treu the archaeologist, who published the sculptures of Olympia, claimed in 1897 that one of the four conceivable arrangements (Open "A": $\mathrm{K}-\mathrm{G}-\mathrm{H}-\mathrm{I}-\mathrm{F}$ ) is physically impossible, because the left hand of figure $\mathrm{K}$ and the spear in the right hand of $\mathrm{G}$ do not fit but run across each other in the limited space [1]. To support this rather strong argument, Treu added that with the help of the plaster models, anyone can verify his statement. Indeed, during the following decades, several archaeologists exploited the possibility and experimented with the life-size models: they concluded that the reconstruction proposed by Treu had to be modified at some major points, yet none of them advocated the option excluded by him $[12,13]$. The large plaster models (kept in Dresden) were not used for experimentation after the World War II; in fact their sheer existence fell into oblivion. (It is a something of a miracle that they survived the notorious demolition caused by the bombings of the city.) Most scholars used either the reduced models or just simple drawings to propose new reconstructions. Besides a great number of studies, a complete monograph was also published on the east Pediment in 1970, but no-one was able to present a fully satisfactory and convincing reconstruction. It is 
characteristic of the situation that a pair of renowned English-Greek authors presented two completely different reconstructions side by side in the same volume on the sculpture of the temple [2]. There was a major methodological problem as well. In general, scholars were accustomed to discuss the reconstruction and the interpretation together and the reconstruction was normally adapted to the interpretation, which is logically the wrong way, of course; evidence, which could be used to establish the correct reconstruction independently from the interpretation, was usually neglected. After a while it seemed that all conceivable arguments have been formulated and no approach proved to be entirely viable, thus archaeologists grew tired of a seemingly unproductive debate and gradually agreed (during the 1970s and 1980s) on a reconstruction, which was proposed by a few authoritative scholars supporting their notion by some theoretical considerations of supposed universal validity [3,5,6]. Thus an absurd situation emerged: today the most widely accepted reconstruction (Figure 3) is precisely the one, which was deemed technically impossible by Treu. Obviously, this would not present a problem, if his results had been thoroughly tested and clearly refuted, i.e. if anyone had showed that Treu had experimented with ill-restored models or had come to wrong conclusions for some other reason. Instead, everyone (with honorable exceptions) has ignored his arguments and his results. Apparently nobody realized that the best evidence for the benefit of experimenting with life-size models is provided by G. Treu himself, who had advocated the arrangement widely accepted today, while he only had the miniature models at his disposal, but later his experiences with the life-size models made him change his mind [1].

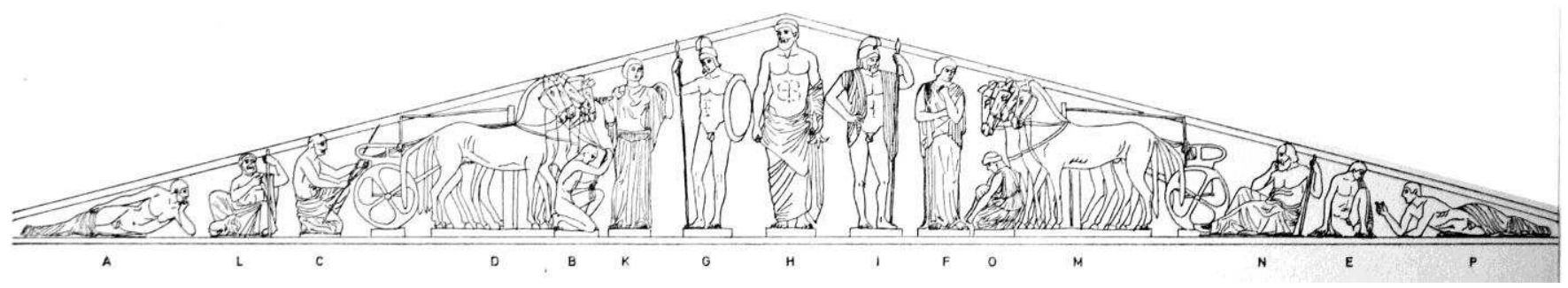

Figure 3. The most commonly accepted reconstruction (open arrangement "A") of the pediment (after Herrmann 1972 fig. 95)

\section{THE PROJECT}

In order to avoid the methodological pitfalls of previous approaches, the present project focused exclusively on the problem of the reconstruction, and did not build upon sources, results, and hypotheses concerning the interpretation of the pediment. It relies exclusively on the following types of evidence, which are totally independent from the interpretation: (1) the size of the sculptures and the elaboration of certain details, which provide a clue about their position in the pediment (optical corrections); (2) the architectural framework of the group (primary context); (3) the position of the excavated fragments at the site (secondary context). The directions indicated by Pausanias (which are also independent of the interpretation) are not discussed here, because this is mainly a philological problem and has already been treated by the author in detail elsewhere [11]. The basic idea of the project consisted in the assumption that 3D scanning and modeling might solve the problem of the arrangement of the central figures of the east pediment of the temple of Zeus at Olympia. Instead of the expensive and troublesome experimentation with plaster casts and models, highly accurate virtual 3D models of the statues can be produced by scanning the extant fragments in 3D and then modeling the missing parts virtually. Inserted in the virtual model of the pediment, these 3D models can be easily used to test the technical feasibility and aesthetic effects of the different reconstructions. This seemingly simple notion was not easy to implement. High resolution 3D scanning can be readily used to create an accurate, undistorted documentation of geometric shapes and surfaces of relatively small size, but the scanning of huge marble sculptures such as the fragments of the Olympian pediments is an especially complicated task and presented a great technical challenge. Practical difficulties of various kinds were experienced during the data capture [14, 15] and the virtual modeling was also complicated. Several software application had to be tested for the effective virtual reconstruction, thus active cooperation with the software developers to find the most appropriate solutions was inevitable. The plan was, however, carried out successfully and the virtual 3D reconstruction of the entire pediment was completed by January 2011. (Figure 4) Since then, the completed model can effectively be used for experimentation with the different arrangements and yielded unexpected results, which were already presented at an international level.[16] Further possibilities to exploit the scanned data and the models (both for scholarly and for educational purposes) are plentiful. The 3D models of the individual fragments can be used for e.g. to visualize the reconstruction of the lost metal attachments of the statues, or they can be inserted in a virtual 3D model of the entire temple. 


\section{THE INTERACTIVE CD-ROM (ISBN 978-963-284-196-0)}

\subsection{Objectives}

During the course of the project reports were regularly presented on various meetings and international congresses and the results were published in due course $[14,15,16]$, but all these publications (both digital and printed media) were restricted to 2D format and did not enable visualization in 3D. An appropriate documentation in the present case can, however, be conceived only in $3 \mathrm{D}$ and the most convenient solution seemed to be the publication of an interactive, multimedia CD-ROM. Our goal was to present the 3D models in a fairly good resolution and in a way, which enables the user to manipulate (to rotate, to zoom, to move) them in a relatively easy and uncomplicated fashion, without the need to purchase costly software products (and to learn, how to use them). At the same time, to preserve intellectual property rights, we did not want to disclose the original 3D data captured or created during the project. (They can be obtained on request - mainly for scientific purposes with no commercial implications - from the author, if both the German Archaeological Institute and the Greek authorities agree.). Since the project is a multidisciplinary one making use of the latest technological innovations and concentrating on a very specific and complex archaeological problem, it seemed to be reasonable to envisage a mixed audience consisting of both classical archaeologists / students of art history and computer scientists / experts in multimedia visualization. The inclusion of at least some pieces of basic information for both groups was deemed to be essential. Because the monument investigated during the project, the temple of Zeus and its sculptures are very well-known and famous pieces of the European cultural heritage (the site itself belonging to the UNESCO World Heritage), it was intended to present the project and the models at different levels, not only for specialists, but also for the interested general public.

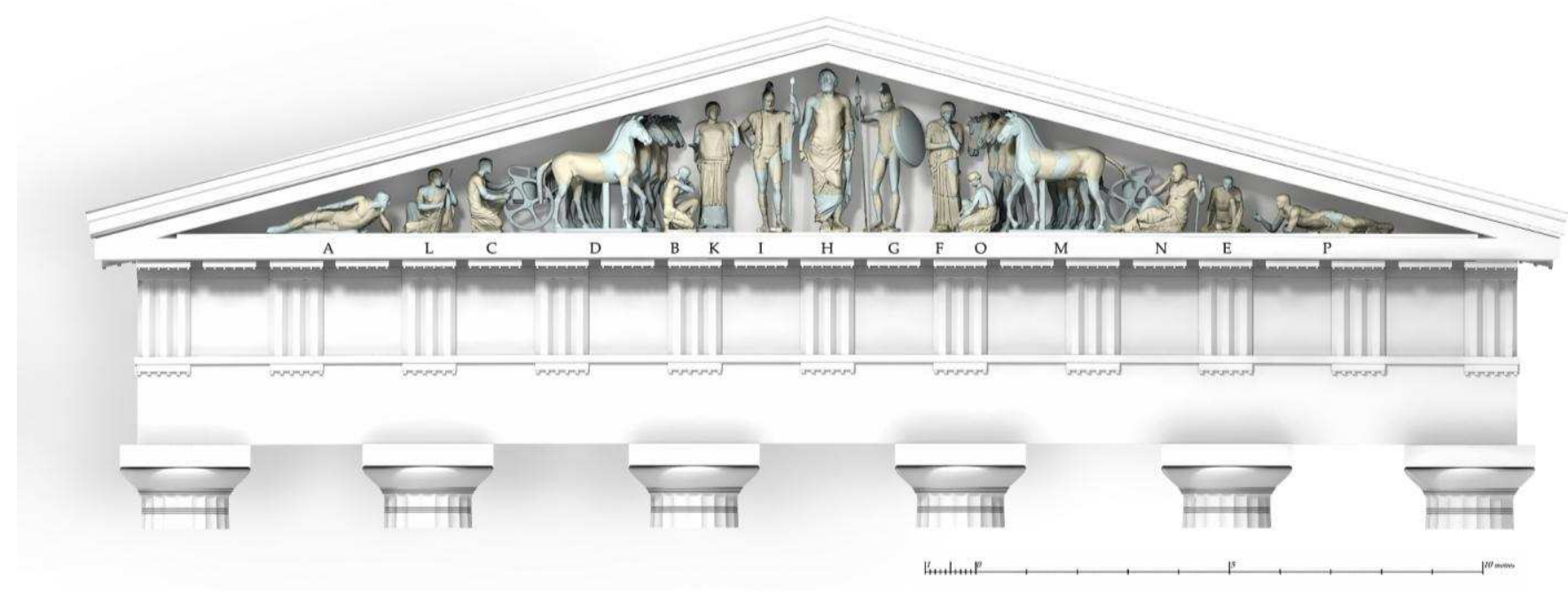

Figure 4. The new virtual reconstruction (closed arrangement "A") of the complete pediment

\subsection{Structure and content}

Our aim was to create a clear and logical structure enabling easy orientation and navigation for every interested party. We chose therefore a format, which combines the appearance of a traditional printed publication with the extended functions of a website. By inserting the CD-ROM into the computer (PC or Mac), the user is automatically confronted with a screen, which functions like an ordinary website with an animated flash intro and a dynamic, multi-level menu (Table of contents) on the left. The content itself is structured in fact like that of a book and the appearance resembles that of a printed book as well (all pages numbered consecutively and having clearly defined dimensions and a constant layout fitting the screen). The pages cannot be scrolled down, but there are arrows on the left and on the right of each, to turn over to the following or to the previous one. In addition there is a navigation bar on top of each page, directly below the title. By clicking on this, a complete scrollable list of all pages (with their individual titles) appears on the screen and the user can easily move to any other page, he is interested in. (Figure 5). The text contains links to attached documents of various kinds (e.g. publications in pdf, reports in mp3 and avi format) and to other pages of the book guiding or informing the user, like cross-references and footnotes of a traditional book. Images and 3D models displayed on the pages can be enlarged and viewed in a separate window by clicking on them. In order to ensure wide and easy usability, 3D models were included in 3D pdf format. This enables the user to observe the models from any 
point of view and to enlarge any part of them, but the original 3D data sets are not disclosed [17]. The fragments of each figure have been generally designated by alphabetic letters since their original publication by G. Treu in 1897 [1] and precisely because their arrangement in the pediment is disputed, they were arranged in alphabetical order, one figure per page. Navigation between them is facilitated for the non-specialists by a page show miniature icons of the models and the commonly used designations of the figures, both functioning as a direct link to the page, where the models of that particular figure are displayed. On these pages, the model on the left shows the surface of the preserved torso as recorded by the $3 \mathrm{D}$ scanner, the one in the centre displays a closed digital model of the piece, whereas each one on the right presents the whole figure as completed during the project, the original parts displayed in grey, the completed ones in pale blue. (Figure 5) Textures taken from the present state of the fragments were not applied to the models, because they are irrelevant for the project and because they are generally misleading, since ancient marbles were originally colored in general, and in this case practically every trace of polychromy has completely disappeared [18].

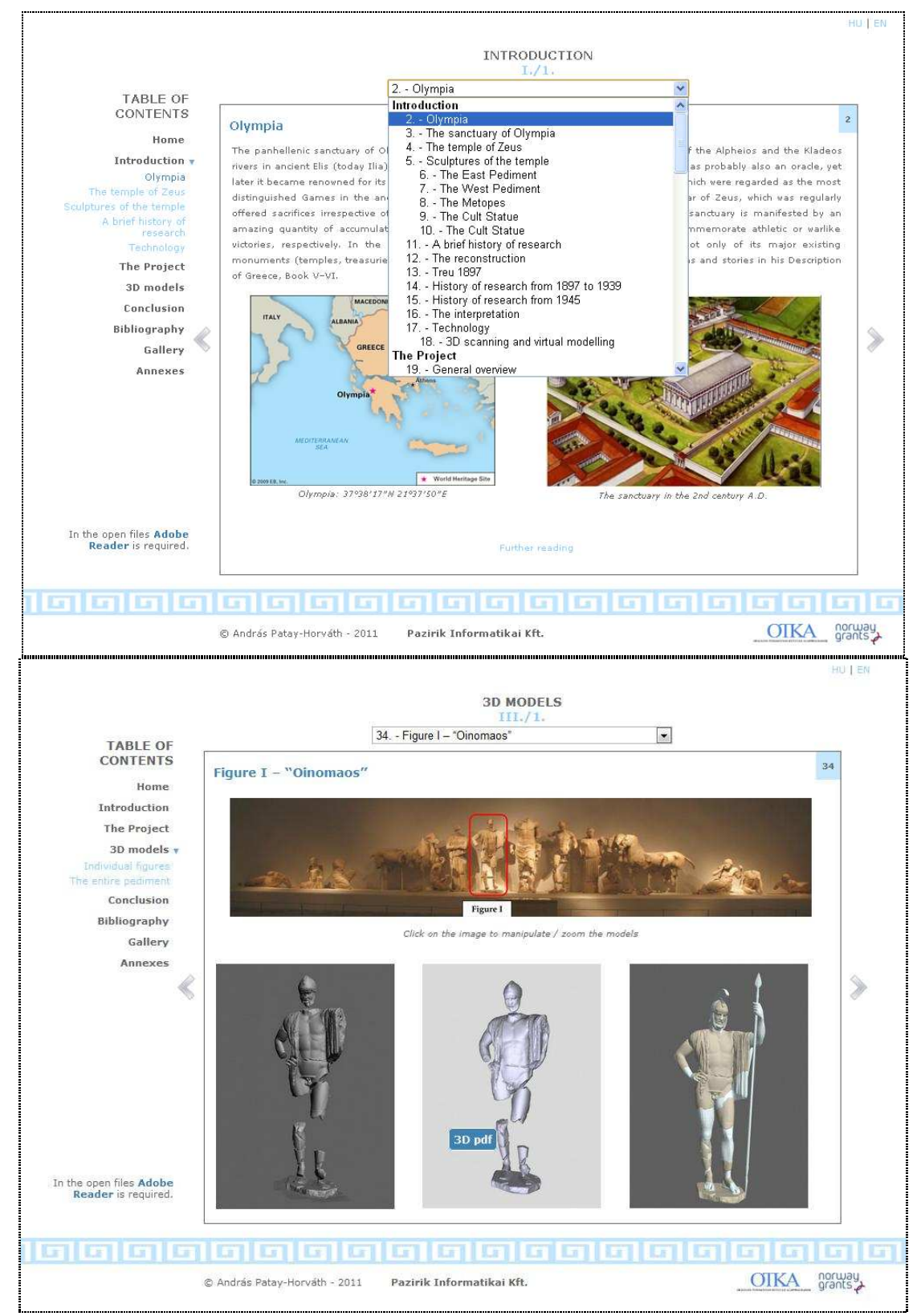

Figure 5. Two pages of the CD-ROM illustrating its main features (structure, navigation, 3D models of individual figures) 
The four different virtual 3D reconstructions of the central part of the pediment are displayed in a similar way (the original and the completed parts differentiated by the same colors and with a navigation aid showing all variants side by side). Two pages are devoted to every single arrangement showing the model from three different but constant viewpoints (all of them on the main axis of the pediment): 1. "museum view" (viewer standing approximately on the same level as the statues); 2. "ancient view" (viewer standing approximately on the ancient ground level before the temple); 3. "aerial view" (from above, pediment frame removed from above the statues). In addition, by clicking on the museum view, each possible arrangement of the central group can be viewed and manipulated in 3D pdf format. With the help of these models, everyone can decide which option seems most or least satisfying technically and aesthetically. The most probable reconstruction of the entire pediment (according to the author) is also included and can be studied in $3 \mathrm{D}$ pdf.

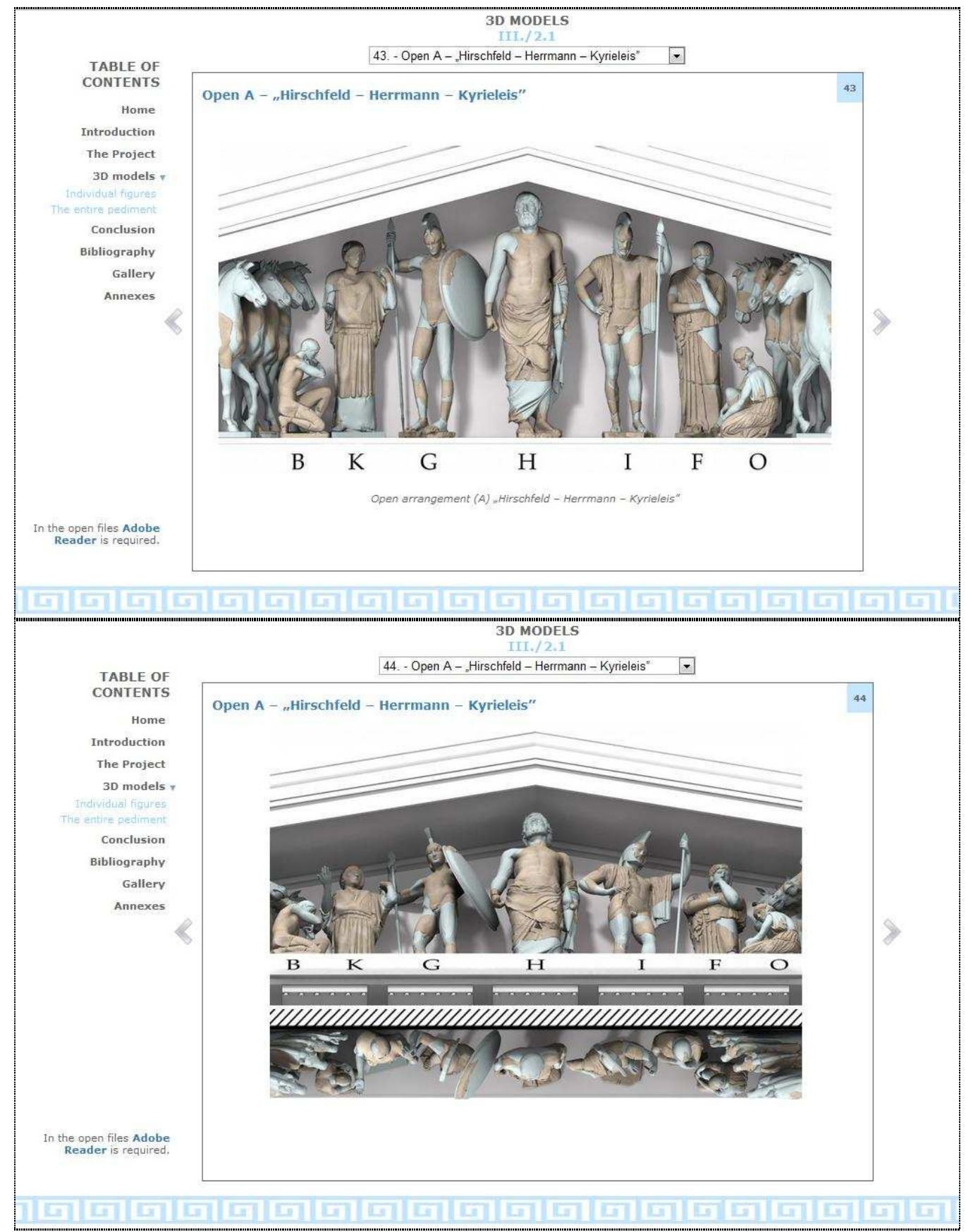

Figure 6. Two pages of the CD-ROM illustrating the presentation of the central group 
Texts, presentations and audio-recordings of lectures, interviews of various genres are displayed in unaltered form (each one of them in the original language, i.e. English, German, Hungarian or French). The differences are due to the various types of audiences (specialists or general public) and reflect at the same time the progress of the research. Published and forthcoming manuscripts of the author are also included in the appropriate sections. Numerous photographs of each figure are also added in the Gallery section and may thus be compared with the 3D models. The aesthetic value of these images cannot be denied, but at the same time, they clearly show the limitations of this kind of documentation.

\subsection{Comparison with similar projects}

There are two distinct groups of projects, which invite comparison with the present one. (1) During the last decade, several virtual 3D reconstructions of the sanctuary and of the temple of Zeus have been produced. These recreations (Powerhouse museum, Sydney 2000 and Foundation of the Hellenic World, Athens 2004) were in fact motivated by the growing interest in the Olympic Games and they were thus fundamentally different from the present project regarding their aims, methods and results as well. The attachments in the Annex section are intended to give a quick overview of them. (2) There were, on the other hand, a few notable projects involving 3D scanning and visualization of ancient sculpture, which can be more readily compared with the present one, although they were concerned with other monuments. These projects are mentioned and illustrated in the Introduction of the CD-ROM, because they had a decisive impact on the present project. The most recent one was the Trier Constantine project (ArcTron Ltd., 2007), which involved both 3D scanning and virtual 3D reconstruction [19] and thus provided the basic idea for the author. The earlier one, ("Metopes of Selinunte" by SIBA, Lecce - NRC, Ottawa, 2004), which involved only the scanning and visualization of Greek sculpture (but actually of the sculptural decoration of a monumental Greek temple, like the one at Olympia), served as a model for the CD-ROM. [20] Despite the similarities of all these projects, the CD/DVD presentations of them became very different in many respects. The Constantine project was advertized only on a DVD by a 12-minutes movie illustrating the workflow and containing some very impressive 3D renderings and animations. The production of such documentation was beyond the means of the present project and would also have been insufficient to convey its results appropriately. The Selinunte CD used Macromedia Director and contains almost exclusively audiovisual material (whereas in our case the material was mainly presented in written form), but its basic structure could be adapted. Our renderings and animations are (mainly for financial reasons) clearly less elaborated and the design of the CD is much less sophisticated than the "Metopes of Selinunte", but perhaps the structure is clearer and the navigation easier. The main difference and the progress can be observed in the rendering of the 3D models, since the 3D pdf format enables a manipulation practically free of any constraints (as opposed to the Quick Time Viewer used on Selinunte CD). The other differences derive mainly from the different aims of the two projects: the Selinunte CD focuses on technology using the archaeological material as an example without discussing it in detail, whereas the CD presented here focuses on an archaeological problem using 3D scanning technology as a tool to solve it.

\section{CONCLUSIONS}

The complete virtual 3D reconstruction of the composition leads to the conclusion that the reconstruction, which is most widely accepted today (Open "A"), is technically the most difficult to realize and that both open arrangements would be feasible only if we ignored a general pictorial convention of ancient Greek art. Still, it is important to emphasize that the virtual reconstruction does not enable us to establish the right arrangement, i.e. the one actually realized in antiquity, but only to exclude (with a high degree of probability) two of the four options. However, considering the uncertainties experienced so far, this result can be regarded as a great progress. Though the remaining two closed arrangements are possible both technically and iconographically, one can observe, that every piece of evidence, which is independent from the interpretation actually point to type "A", which can be considered therefore as the most probable reconstruction. The project reached therefore its major goal and contributed significantly to a debate, which engaged archaeological research for more than a century. It demonstrated at the same time, that 3D scanning can be used not merely for documentation (as it is most frequently employed), but for effective research purposes as well.

\section{ACKNOWLEDGEMENTS}

The scanning campaign was carried out with the permission of the 7th Ephorate of Prehistoric and Classical Antiquities in Greece and in close collaboration with the German Archaeological Institute at Athens, conducting the excavations on the site for more than 125 years. Special thanks are due to G. Hatzi (head of the Ephorate at Olympia) and R. Senff (archaeological supervisor of the Olympia excavations). Financial support for the project was provided by the Hungarian National Research Fund (OTKA ref. no. NNF 85614) and the János Bolyai scholarship offered by the Hungarian Academy of Sciences. 


\section{REFERENCES}

[1] Treu, G.: Olympia III. Bildwerke aus Stein und Thon. Berlin, 1897.

[2] Ashmole, B. - Yalouris, N.: Olympia. The Sculptures of the Temple of Zeus. London: Phaidon, 1967.

[3] Simon, E.: Zu den Giebeln des Zeustempels von Olympia, Mitteilungen des Deutschen Archäologischen Instituts, Athenische Abteilung 83 (1968), 147-167.

[4] Säflund, M. L.: The East Pediment of the Temple of Zeus at Olympia. A Reconstruction and Interpretation of its Composition. Göteborg, 1970.

[5] Herrmann, H.-V. (ed.): Die Olympia Skulpturen. Darmstadt: Wissenschaftliche Buchgesellschaft, 1987.

[6] Kyrieleis, H.: Zeus and Pelops in the East Pediment of the Temple of Zeus at Olympia, in: Buitron-Oliver, D. (ed.)

The Interpretation of Architectural Sculpture in Greece and Rome. Washington: National Gallery of Art, 1997, 12-27.

[7] Rehak, P. - Younger, J. G.: Technical observations on the sculptures from the temple of Zeus at Olympia, Hesperia 78 (2009), 41-105.

[8] Patay-Horváth, A.: Pausanias und der Ostgiebel des Zeustempels von Olympia, Acta Antiqua Acad. Hung. 44 (2004), 21-33.

[9] Patay-Horváth, A.: Die Frisur der weiblichen Protagonisten im Ostgiebel des Zeustempels von Olympia, in:

Ganschow, Th., Steinhart, M. (eds.): Otium. Festschrift für Volker Michael Strocka. Remshalden: Greiner, 2005, 275283.

[10] Patay-Horváth, A.: The armor of Pelops, in: Mattusch, C. C., Donohue, A. A. , Brauer, A. (eds.): Common Ground. Archaeology, Art, Science and Humanities. Proceedings of the XVIth International Congress of Classical Archaeology Boston. Oxford: Oxbow, 2006, 424-427.

[11] Patay-Horváth, A.: Zur Rekonstruktion und Interpretation des Ostgiebels des Zeustempels von Olympia, Mitteilungen des Deutschen Archäologischen Instituts, Athenische Abteilung 122 (2008), 161-206.

[12] Studniczka, F.: Die Ostgiebelgruppe vom Zeustempel in Olympia, Abhandlungen der Sächsischen Akademie der Wissenschaft, Phil.-Hist. Klasse 37 (1923), 3-36.

[13] Bulle, H.: Der Ostgiebel des Zeustempels zu Olympia, Jahrbuch des Deutschen Archäologischen Instituts 54 (1939), 137-218.

[14] Patay-Horváth, A.: Virtual 3D Reconstruction of the East Pediment of the Temple of Zeus at Olympia - A Preliminary Report, Archeometriai Mühely / Archaeometry Workshop 7/1 (2010), 19-26.

[15] Patay-Horváth, A.: Virtual 3D Reconstruction of the East Pediment of the Temple of Zeus at Olympia - A Preliminary Report, Proceedings of the 14th International Congress "Cultural Heritage and New Technologies" 2009, Wien, 2011, 653-658.

[16] Patay-Horváth, A.: The complete Virtual 3D Reconstruction of the East Pediment of the Temple of Zeus at Olympia, http://www.isprs.org/proceedings/XXXVIII/5-W16/pdf/patay.pdf, 2011-05-30.

[17] Pletinckx, D.: Europeana and 3D, http://www.isprs.org/proceedings/XXXVIII/5-W16/pdf/pletinckx.pdf, 2011-0530.

[18] Brinkmann, V. - Primavesi, O.: Die Polychromie der archaischen und frühklassischen Skulptur, München: Biering und Brinkmann, 2003.

[19] Parisi Presicce, C.: Konstantin als Iuppiter, in: Demandt, A. - Engemann. J. (eds.): Konstantin der Grosse. Imperator Caesar Flavius Constantinus., Darmstadt, 2007, 117-131.

[20] Beraldin, J.-A. (et al.): The metopes of Selinunte: Presentation of the interactive CD-ROM, XXI International CIPA Symposium, http://cipa.icomos.org/text\%20files/ATHENS/FP025a.pdf, 2011-05-30. 